\title{
Will Mobile Learning Bring a Paradigm Shift in Higher Education?
}

\author{
Lalita Rajasingham \\ School of Information Management, Victoria University of Wellington, P.O. Box 600, Wellington 6014, New Zealand \\ Correspondence should be addressed to Lalita Rajasingham, lalita.rajasingham@vuw.ac.nz
}

Received 22 September 2010; Revised 10 November 2010; Accepted 16 December 2010

Academic Editor: Jan Elen

Copyright () 2011 Lalita Rajasingham. This is an open access article distributed under the Creative Commons Attribution License, which permits unrestricted use, distribution, and reproduction in any medium, provided the original work is properly cited.

In the light of technology-driven social change that creates new challenges for universities, this paper considers the potential of mobile learning as a subset of e-learning to effect a paradigm shift in higher education. Universities face exponential growth in demand for higher education, significant decreases in government funding for education, a changing in understanding of the nature of knowledge, changing student demographics and expectations, and global competition. At the same time untethered mobile telephony is connecting large numbers of potential learners to communications networks. A review of some empirical literature on the current status of mobile learning that explores alternatives to help universities fulfil core functions of storage, processing, and disseminating knowledge that can be applied to real life problems, is followed by an examination of the strengths and weaknesses of increased connectivity to mobile communications networks to support constructivist, self-directed quality interactive learning for increasingly mobile learners. This paper also examines whether mobile learning can align the developing technology with changing student expectations and the implications of such an alignment for teaching and institutional strategies. Technologies considered include mobile computing and technology, wireless laptop, hand-held PDAs, and mobile telephony.

\section{Introduction}

Universities today face new challenges. Exponential growth in the demand for higher education, significant decreases in government funding for education, the changing nature of knowledge, changing student demographics and expectations, and global competition [1] in the provision of higher education and rapid advances in information and communications technologies demand a reexamination of how universities fulfil their core functions of storage, processing, dissemination, and application of knowledge to reallife problems $[2,3]$.

The nature of paradigms is discussed here from the perspective of Thomas Kuhn's definition. According to Kuhn a paradigm is "what members of a scientific community, and they alone, share" [4, page 294] and "when paradigms change, the world itself changes with them" [5, page 110]. The inference is that paradigms shift when a society or community as a whole accept and practice the changes it brings.
Over the ages universities have undergone many conceptual paradigm shifts in what and how they teach and to whom. Medieval theological elitist universities became modern industrial universities. Emerging virtual universities are attempts by institutions of higher education to change with time in order to remain relevant in the future.

The effects of the digital age on higher educationconcepts such as e-learning and mobile learning ( $\mathrm{m}$ learning)_are subjects of interesting academic research. They seem, however, to be somewhat divorced from the dayto-day realities that currently face students and teachers.

In the last three decades numerous approaches have appeared to adopt information and communication technologies for the purpose of learning and education. The term "e-learning" was accepted for expressing the effort to transform educational processes through application of different up-to-date electronic media and to customize learning to students' needs in terms of study style, culture, time, and space. The dramatic growth of local and wide area computer networks accelerated the evolution of the Internet 
and growth of online education, web-based education, education via computer-mediated communication, and virtual education [6]. Quality in any new educational approaches is critical, and a useful framework for evaluation is provided by the Sloan Consortium [7].

In assessing the potential of m-learning as a subset of e-learning to effect a new paradigm of higher education, this paper seeks a mobile-learning approach that retains the original DNA of distance education which has developed into numerous subtle derivatives, to evaluate the use of mobile technologies that increase access to education for increasingly mobile learners seeking just-in-time and justfor-me education outcomes. Technologies considered in this context are mobile computing and technology, wireless laptop, iPads, mobile phones such as Blackberry, iPhones hand-held personal digital assistants (PDAs), and mobile telephony.

While mobile phone subscribers in the developed world are growing rapidly, in the developing world, especially in Africa, China, India, and Indonesia because of the lack of landline telephony and associated implementation costs, mobile phone subscribers are increasing; see Figure 1.

According to Ng'andwe [8] the African continent has stunned the world by leapfrogging several stages of traditional telecommunications development. The mobile phone has become commonplace even in many of the poorest countries. By 2009, about one-third of the African population had a mobile phone subscription-as opposed to only $8.7 \%$ using the Internet through desktop computers [9]. With approximately 360 million cell phone subscribers, Africa has surpassed the USA (270 million subscribers), according to UNCTAD [10]. And eLearning Africa [11] points to there being still great potential for further development.

However, mobile phone use in education globally is still low. In an exploratory approach, this paper reviews some current empirical findings on the relatively recent phenomenon of m-learning that is characterised by technological mobility, instability, and uncertainty, as theoretical, andragogical, and organisational structures of m-learning are still being developed.

Advances in the Internet and wireless applications are considered as an extension of the framework provided by more traditional e-learning environments to support constructivist, self-directed interactive learning that helps to develop a sustainable global learning system that aligns the technology to respond to changing student expectations [1].

\section{Access Enabling ICT Advances}

Given the exponential worldwide growth of consumer electronic devices such as cell phones and PDAs, it would be difficult to refute the argument that the spread of mobile communications is one of the most significant events of the last 10 years. It is a double-edged sword. As reported in the media, the Internet, blogs, twitter, Facebook, and so on, today, powerful new mobile communications technologies such as pocket-sized wireless telephony are launching

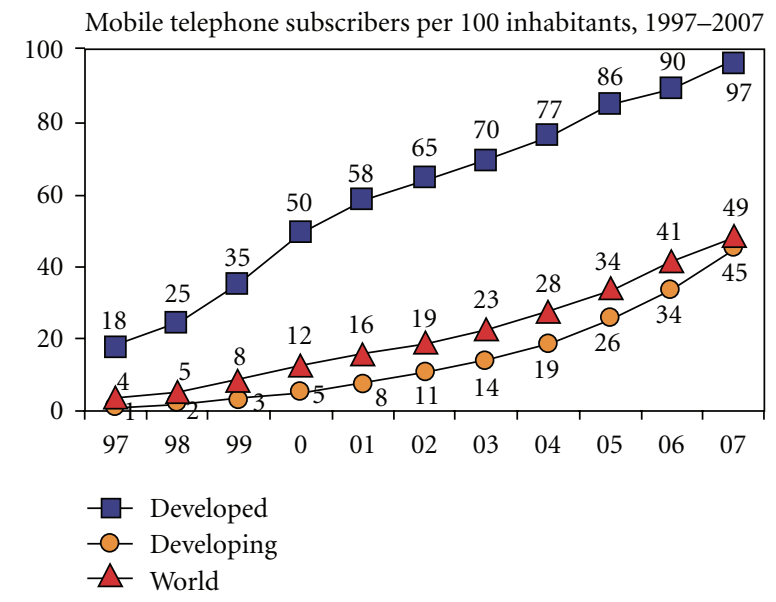

FIGURE 1: Source: http://www.itu.int/ITU-D/ict/statistics/ict/index .html.

democratic revolutions, surveillance capabilities, revolutionising diagnostic medicine, and natural disaster communications and are at the forefront of economic transformations and social and ideological upheavals in both developed and developing economies.

The Internet is a global communications tool par excellence. Essentially, it is a public and private conversational tool. While the telephone was the ultimate private, oneto-one communications tool, the advent of networking technologies, digitalisation, and the Internet means the telephone now provides the most comprehensive technological communications platform in existence for anyone, anywhere, in any mode, and at any time communications.

Since 1995, Tiffin and Rajasingham have provided in their seminal texts the philosophical framework for a global virtual university as a new paradigm for the university. Research publications cited in Google, for example, validate some of the empirical theses and hypotheses advanced in these texts. The texts $[2,3]$ argued that ICT will affect every aspect of human endeavour and will have a particularly important effect on higher education, changing university paradigms. But there is now an extension to this thinking, as mobile communications allow networks to embed themselves not only in social and political organisations but also in the delivery of just-in-time, just-for-me access to personalised education that is different from previous actualisations of PC-based platforms.

Education policymakers and planners must first be clear about the educational outcomes being targeted. Broad goals should guide the choice of the technologies to be used and the modalities of their use. Haddad and Drexler [12] suggest that the potential of each technology varies according to how it is used and identify at least five levels of the use of technology in education: presentation, demonstration, drill and practice, interaction, and collaboration.

The question here is whether it is the right time to assess the potential of new approaches, such as m-learning, to constitute a new paradigm of learning in Kuhnian terms, when these novel approaches have yet to move from 
experimental pilot project status to mainstream status [13]. The next section presents an overview of some current developments in the relatively new phenomenon of $\mathrm{m}$ learning and to identify issues that need to be addressed before it can be determined if m-learning can constitute a paradigm shift in higher education in the knowledge society.

\section{Defining, Discussing, and Evaluating Mobile Learning (m-Learning)}

There are a few schools of thought that provide definitions of m-learning. An influential researcher in the field, Mike Sharples (2004), broadly defines it as Learning away from one's normal learning environment or learning involving the use of mobile devices [14].

A useful definition of m-learning is provided by the eLearning Guild [15]:

An activity that allows individuals to be more productive when consuming, interacting, or creating information, mediated through a compact digital portable device that the individual carries on a regular basis and has reliable connectivity and fits in a pocket or purse.

M-learning is enabled by the convergence of computers and telecommunications, the Internet and digitalisation. Digitalisation, the principal innovation in communications technology in the last decade, allows the creation of immersive environments in which all forms of information, whether visual, graphic, moving, or auditory, can be stored digitally in reusable and portable form in learning object repositories (LORs). Such environments are able to be conveniently accessed, and elements can be mixed appropriately for alternative and complementary approaches to teaching and learning [16].

3.1. Time and Place for m-Learning: Some Examples. It is suggested that it is the contextual use, that is, when and in what circumstances m-learning occurs, is critical. As noted before, m-learning is in a pilot stage, where projects are being developed in an effort to move this approach from experimental to mainstream status. For example, many museums worldwide use hand-held mobile technology as an educational resource. Students interact with the exhibits with quick, sharp questions, and communicate through SMS with instructors/museum personnel in order to gain collaborative knowledge. See http://www.wellingtonnz.com/school_trips/ museum_wellington (accessed 15 August, 2010).

Goh and Hooper [17] developed a potential use of a mobile phone Short Message Service (SMS) crossword puzzle system to promote interaction through learning activities in a large undergraduate classroom environment at Victoria University of Wellington, New Zealand. While personal response systems (PRSs) have been used in the classroom environment to foster interaction, the researchers conclude that it is not an ideal tool, with respect to cost and functionality.
The MobiClass developed by the E-Learning Lab of the Shanghai Jiao Tong University is a useful example of significant research into the culturally appropriate use of $\mathrm{m}$ learning in blended (face-to-face) and online learning pilot initiatives in Chinese universities [18].

Doering [19] notes that, because mobile learning scenarios are restricted to short-lived, funded pilot projects and institutions outside mainstream methods and institutions, her university in Germany established a research team in 2006 to overcome the marginal status of m-learning. Her paper outlines the mainstreaming strategy that was guided by six pedagogical, technical, and organisational criteria and suggests that, from a mainstreaming perspective, teachers and learners must first articulate a need for m-learning.

Traxler [20] usefully adds to the research in m-learning and notes the increasing development of communities of practice in m-learning, which is distinct from the established communities of tethered e-learning.

Some advocates of m-learning attempt to define and conceptualise it in terms of devices and technologies, others in terms of the mobility of learners and the mobility of learning, and others in terms of learners' experience of learning with mobile devices [21].

Metcalf [21] notes: "I use my handheld devices for "stolen moments of learning" so that I can eke out a little more productivity in my day by learning while standing in line for the bank or waiting for an appointment...." In his presentation Metcalf suggests that, because the way we live, work, play, and learn is being affected by the increasing mobility of our society, it is the responsibility of educators and learning innovators to design for the needs of education's changing audience. It is suggested that learning is akin to constructing a narrative or a conversation, and the question remains as to whether "stolen moments of learning" can lead to constructivist scaffolded deep learning that would constitute a new university paradigm in mobile learning environments.

A main challenge for online learning providers is to gain accreditation by national quality regulators and accrediting bodies for their programmes. A Google search (30 May 2010) on quality accreditation for m-learning programmes came up with more than 1.5 million hits, with none that specifically identified m-learning. In the current environment, universities seek to demonstrate the quality of their services in ways that are attractive to potential students, employers, university administrators and staff, regulators, and government accrediting agencies. Romiszowski [22] notes that the many plausible attempts to define quality standards and best practices for online education have done little to assuage the scepticism of representatives in the academy, who are more accustomed to face-to-face delivery directed to bounded communities.

Caudron [23] cites Schank, who suggests that in many cases the potential of electronic delivery modes has not been fully realised in the execution of online courses as the result of trying to replicate the classroom environment, instead of maximising the new configurations of knowledge creation and facilitating community formation in an interactive online communications environment. 
A prime example of a successful e-learning institution is the 15-year-old Universitat Oberta de Catalunya (UOC) (the Open University of Catalonia) based in Barcelona, Spain. The UOC is a $100 \%$ internet-based university and is the world's first continuous and sustainable Virtual University, having grown from 200 students in 1995 to a student community of over 55,000 (six thousand international) and still rising. One of the strengths of the UOC is that it was accredited at inception as one of the eight public universities serving the Catalan community. Unlike many virtual universities, online and e-learning initiatives that were part of, albeit peripheral to, activity in dual mode face-to-face universities, the UOC, with no conventional university baggage to contend with, developed a new university paradigm as a holistic system, where students wishing to enrol went into a virtual campus that channelled them through the education processes up to graduation, and alumni activities, all online (http://www.uoc.edu/). However, students at the UOC are increasingly demanding that social network tools should be integrated into their Virtual Campus for synchronous communications [1].

\section{Current Status of Academic Research on m-Learning}

Mobile Communication and Society: A Global Perspective [24] provides a comprehensive coverage of the disparate body of research on the social dimensions of mobile communications in the last decade, including sociology, communications, geography, digital divides, spatial relationships, language, civil society, and economic development. While a search of the literature on the current status and application of e-learning, virtual universities, and m-learning provides, in many ways, empirical validation of some of the theses advanced in the research in the application of ICT to education [2, 3, 24-28], research in sustained successful application of mobile technology for achieving optimum learning outcomes and alignment between learner/teacher expectations and the generation of new skills in response to societies' needs is still scarce.

However, the indications are that m-learning is more successful in corporate education than it is in mainstream higher education. A useful concept when discussing success and failure relates to the term "disruptive technologies," a term coined by Christensen [29] and introduced in his 1995 article Disruptive Technologies: Catching the Wave. His thesis on the principles of disruptive innovation suggests that good companies failed because their managers either ignored those principles or chose to fight them.

Robert Birnbaum, in applying Christensen's theory of disruptive innovation [29] to the field of online higher education, suggests that higher education must be free to create an entirely new kind of organisation and comes to the following conclusion:

The logical conclusion of applying the theses of The Innovator's Dilemma and The Innovator's Solution to higher education may be that virtual education can thrive in traditional colleges and universities only if it operates outside their normal management and value frameworks, with the risk of losing institutional control [30]. Would this concept of disruptive technologies as applied to m-learning delay it from effecting a paradigm shift in the Kuhnian sense?

For further review of innovations in US higher education, see [31].

Education as a service industry has had its share of failed applications of ICTs. The histories of the rise and fall of the use of ICT in education, such as educational television, programmed instruction, and several other promising new applications of technology to education, have already been written [2]. Castells et al. [24] suggest that mobile technologies are disruptive technologies. This paper documents some failures in m-learning so that an analysis of the reasons for such failures may help in the understanding of the pitfalls and challenges currently facing $\mathrm{m}$-learning initiatives to become mainstream $[13,24]$.

A useful paper by Roschelle and Pea, entitled A Walk on the WILD side: How wireless handhelds may change CSCL [32], suggests that designs for Computer-Supported Collaborative Learning (CSCL) applications usually presume a desktop or laptop computer. Future classrooms are likely to be organized around Wireless Internet Learning Devices (WILD) that resemble graphing calculators, Palm, or PocketPC handhelds connected by short-range wireless networking $[18,32]$.

Roschelle and Pea's paper is one of the very few useful papers on the subject and inspired the author of this paper to examine the potential of m-learning in higher education and to examine whether Roschelle and Pea's predictions about the promises of ICT are being realised, and if not, why not.

Publications and conferences on m-learning continue to proliferate on the Web. A search for the term "m-learning" on Google.com resulted in 966,000,000 hits on 17 January 2010, compared to $338,200,000$ hits on 9 January 2009. But many of the initiatives referenced are in pilot status and provide negligible documentation of their progress when the sites are revisited.

In the last two decades a focus of academic research into higher education has been new paradigms of teaching and learning. However, the resulting empirical evidence suggests that those universities and other organisations that opted for online learning, and especially m-learning, found that their various expectations were not fully met [33].

Retrospective accounts point out that the failure of elearning projects was due not to inherent weaknesses or inadequacies in the technologies, but rather to errors made by people and institutions in the process of implementing the innovations [30], especially in instructional design and staff development programmes targeting new approaches such as $\mathrm{m}$-learning. If the causes of failure have more to do with the actions of people and organisations rather than with inherent limitations of the technologies and tools, those in learning organisations need to find more effective ways of delivering the promise of new technologies.

Many issues regarding m-learning are yet to be resolved. Motiwalla [34] suggests that most existing typical e-learning systems are tailored toward PC-based web access and are not customised for use through mobile devices such as 
PDAs for synchronous learning. Furthermore, the content developed in most of these systems is not standardised, making reuse difficult, and there is urgent need to develop an affordable architecture for and prototype of a mobile learning system that can operate on both PC and mobile platforms. New platforms such as Flash Lite and the Leonardo da Vinci Project that have capability are proprietary and commercial and are often beyond the financial means of students.

\section{In Search of a Theoretical Approach for Online Education}

$\mathrm{m}$-Learning is a specialised form of conventional e-learning, and wireless networks are the fastest growing communications technology in history [24]. Mobile devices are not reliant on fixed-line telephony for instant communications and are "personal, portable, pedestrian" [35]. The mobile phone with $3 \mathrm{G}$ capability and cloud computing is becoming a multifunctional computational tool, a wearable accessory that, in addition to its main function of interpersonal communications, is now used for a wide range of social practices [35, 36]. However, its potential for facilitating learning is a new phenomenon that has spread through the use of mobile ICTs that blur the boundaries between communication and computation and combine ubiquity and utility, challenging traditional pedagogy and andragogy and offering complementary approaches [37].

Moore describes the education process where teacher and learner are separated by distance, time, or choice as "transactional distance" [38] thus emphasising the importance of communication between teacher and learner. This communication is enabled by ICTs.

Education is a kind of communication [2]. Simple as it may seem, this conceptual definition is yet to be challenged. Open learning, e-learning, online learning, virtual education, and m-learning approaches of today as tools of "proximate" education are subsets of distance education. They fall into the rubric of "technology-mediated learning," which, according to Daniel [39], provides a unifying theme for many educational developments these days.

Adapting Vygotsky's [40] environmentalist concept of education, described as the Zone of Proximal Development, Tiffin and Rajasingham [2] provide the basis for looking at education as communications. Communications and information technologies provide the bridge for communications and interaction between learner, teacher, knowledge, and problem as a collaborative process, in synchronous (real-time) systems, such as telephone network systems, and asynchronous (non-real-time) systems, such as most computer and web-based systems, LMS, and email. The nature of each communications medium has a direct impact on the extent and quality of dialogue between teachers and learners.

Tiffin and Rajasingham [2, 3] were researching the reality of educational crises since the 1960s. They suggest that education as a kind of communication involves both social and cognitive connectivity to transmit and process information from situated cognition (from the teacher as part of the educational institution and today as part of the Internet and web-based resources) to acquisition and application of knowledge to enable learners to solve real-life problems.

While the conventional modern university focuses on acquisition of knowledge, in the new rapidly changing mobile knowledge society, higher education is challenged to ensure a better alignment between learner expectations and societies' demand for new kinds of skills and the university's capability to respond.

Here, the theoretical framework as expressed in the Theory of Conceptual Change [41] appears to be relevant. According to the authors, conceptual change occurs when a concept is reassigned from one category to another. When the concepts belong to different ontological categories or domains such as Matter (things) and Processes, then conceptual change becomes difficult and can lead to Incompatibility Hypothesis [41] and by inference faulty reasoning.

It is suggested that, in the neo-Vygotskyian model, there is no difficulty with conceptual change because both education and communication belong to the same category (or domain). Both categories are based on matter, atoms (building and transport technologies), and communications between teacher/learner/knowledge, and problems are processes (of information) based on energy, where the human brain and today the computer processes the information to generate new information/knowledge.

Tiffin and Rajasingham [3] note that, at a time of worldwide exponential growth in demand for higher educational opportunities and as the costs of transport and building technologies increase, it is more efficient and effective to bring teachers and students together using telecommunications and computing infrastructures, particularly the Internet, where teachers help learners apply knowledge to real-life problems. The Internet, as it makes greater use of fibre optic, satellite, and wireless technologies, is rapidly creating fully immersive, worldwide broadband communication networks that rival face-to-face communication in terms of effectiveness, liberating learning from constraints of time, speed, and space and offering e-learning/virtual education and m-learning on both national and global scales [3]. The introduction of new technological tools in existing social environments brings specific patterns of interaction and specific culture and protocols related to each such tool, and such tools often affect or transform existing cultures and practices [42].

It is suggested that the neo-Vygotskyian model as described does introduce a new paradigm as it moves from a teacher-centric to learner-controlled learning systems. As Kuhn [5] argues, natural science theories evolve in paradigmatic shifts from revolutionary to normal sciences. Because social sciences, which include communications and education, are also normative sciences, the moral paradigms are often in conflict, fluctuating between, for example, cultural conflict and consensus, individualism and collectivism, freedom and determinism, conservatism and liberalism, egalitarian and hierarchical norms, and so on $[13,18,29,30]$. In the Kuhnian sense, therefore, m-learning 
cannot effect a paradigm shift until it moves from pilot stage into mainstream higher education and when society accepts the new approach as a paradigm shift.

However, as we look at the move to learner-controlled learning environments, the teacher's role is still critical and is part of the communications teaching paradigm: the teacher's role is still to establish communications between the learner, teacher, knowledge, and problem in an extended network $[2,3]$. Some challenges for learners and teachers in mobile environments are examined next.

\section{Challenges from Learner Perspectives}

The move to offering more mobility and access to education is now occurring at a speed that was difficult to predict just a year or two ago. Increased use of mobile telephones and their convergence with PDAs and similar devices has created new possibilities for providing learning and the development of education on the go (analogous to "food to go") that offers just-in-time learning moments in synchronous mode. Just as "food to go" is regarded as junk food or merely a "hungerbuster," there is ongoing debate as to whether learning on the go can in fact provide "deep learning."

Educational systems serve the societies in which they are located and operate in accordance with the prevailing cultural paradigm and technological infrastructures. When paradigms change, so too must what we teach and how we teach. A critical change this century is in the roles of teachers and learners, brought about by digitalisation, the rapid changes in the breadth and scope of the Internet, and the changing nature of knowledge itself. Changes in the needs of industry in rapidly advancing technological environments demand new kinds of knowledge on the Internet, each culture seeking legitimacy of its knowledge and its application in culturally appropriate ways.

In the prevailing move from teacher-controlled to learner-centred user pays environments, learners as restless digital natives are homesteading on Rheingold's [43] "electronic frontier", playing videogames, and increasingly becoming disengaged with traditional instruction and its dependent technologies. Teachers and management, on the other hand, as digital immigrants, are still bouncing between atoms and bits, clinging to traditional instructional methods, exacerbating the misalignment between changing learner expectations, such as instant solutions to real-life problems, and the ability of the teaching institution to respond.

Oblinger and Oblinger, in Van Eck's [44] article on digital game-based learning, argue that learners demand multiple streams of information, prefer inductive reasoning, want frequent and quick interactions with content, and have exceptional visual literacy skills. Van Eck believes that games embody well-established principles and models of learning, such as the importance of context, where learning is directly related to the environment by being applied and practised within that context. This is referred to as "situated cognition." $\mathrm{He}$ gives further aspects of games' paradigms relevant to e-learning, including anchored instruction, feedback, behaviourism, narrative psychology, and collaboration. The challenge for teachers today is to align the game paradigm with the learning paradigm, which in turn will require addressing a clash of concept change.

\section{Challenges from Teacher Perspectives}

While opportunities exist to cater for new kinds of learner demands, there is an urgent challenge for teachers to redesign instruction to retain intellectual depth in a new, technological, mobile environment. Education is a kind of communication, where the teacher helps the learner to apply knowledge to problems, and as the technology that enables this communication to take place changes so too it will change how we teach and learn. The main challenge for teachers is to design instruction and develop strategies for students on the go, demanding constant and instant communications in minute(s)-long soundbytes, podcasts, and video clips via their mobile phones, PDAs and Blackberries [45]. While mobile technologies provide convenient access, learning is about collaboration between teachers and learners, and between learners, to process information to generate new knowledge that can be applied to real-life problems. The following section highlights some strengths of m-learning that can usefully improve learning from learner and teacher perspectives.

7.1. Strengths of m-Learning. Successful m-learning depends on effectively mediating the binaries of technology and pedagogy. The plain old telephone systems (POTS), the powerful tool for real-time interpersonal communications, has morphed into the Internet, multimedia, and cellular wireless mobile tools of communication. The strength of the mobile phone is that it is the tool par excellence for social connectivity. If students are truly able to study anywhere, anytime, while actively moving around, for example, waiting for or sitting on the bus or doing housework, simultaneously receiving and providing information, and interacting wherever they may be, educational and social communications are inextricably intertwined. However, it must be recognised that placing the functionalities of a virtual class on a tiny palmtop screen is difficult and would involve the challenges of successfully changing concepts $[18,41]$.

In her editorial, Gaskell [46, page 1] poses a critical question: “... is e-learning more related to the medium of delivery; to technological rather than pedagogical concern...?" She suggests that the cell phone has the potential to widen access to education, especially in developing countries such as South Africa, where, according to Brown [47], 99\% of distance students at the University of Pretoria have access to a cell phone while only $0.4 \%$ has access to the Internet.

Lee and Chan [48] suggest podcasting as potential "true" m-learning, with pedagogical value beyond merely using mobile devices to deliver e-learning. See the following latest advertisement from IDEA that highlights the power of mobile telephony in India to address the socially relevant theme of education for all. The thought-provoking ad campaign has Abhishek Bachan, prominent Bollywood actor and producer, playing the head of an educational institution, 
who, when challenged by the traditional, physically bound classroom methodology that prevents reaching out to many more who are in need of education, uses mobile telephony to overcome the barrier [49].

However, like the definitions of virtual learning and elearning, there are varied, overlapping, and still evolving definitions of m-learning [50]. Many authors, for example, Quinn [51], Harris [52], Sharples [14], and Keegan [53], tend to emphasise mobility aspects of the devices used and view m-learning as occurring at any time away from the learner's usual environment for formal learning, such as the home, workplace, or educational institution. But it could be argued that, in the last two decades, virtual learning, elearning, and online learning offered similar anytime, any place learning for anyone. However, the main difference is the move from desktop to mobile, handheld telephone technology that offers the equivalent of Ausubel's Advance Organizers for the learning and retention of verbal material [54].

An advance organizer is information that is presented prior to learning and that can be used by the learner to organize and interpret new incoming information [55]. To facilitate constructivist learning, the posting of, for example, an abstract of a new text or new chapter so students are aware of the overview of the text or of a list of concepts is valuable. Furthermore, learner support systems such as instant connectivity with teachers, and peers, and learning management systems (LMS) that give information on assignment submission dates, examination results, changes of meeting times and locations, cancellation of classes, and similar short information blogs can efficiently be transmitted through SMS. Theoretically, when appropriately designed and well managed, m-learning can improve pedagogy and andragogy by timely learner support systems that provide an extra communications channel for learners and teachers and between learners.

According to Ryu and Shen $[18,56]$, to ensure success of future m-learning, it is essential to develop affordable and effective applications that are matched to the needs and learning styles of users in culturally appropriate ways. Lee and Chan [48] list some attributes of mobile learning applications that are functions of instructional media design. They argue that concepts such as mobility, ubiquity, and spontaneity are simply based on the technologies used and repackaged for mobile platforms and, hence, offer extra value from a pedagogical perspective. However, mobile technologies fail to deliver pervasive learning activities unless this type of learning " ... on the move, while in motion ... is integrated into our daily lives in a completely unobtrusive fashion" [48, page 203]. There is little research evidence as yet that this is happening.

To sum up, m-learning strength includes the use of mobile/handheld pocket devices such as cellular or smartphones, multigame devices, personal media players (PMPs), personal digital assistants (PDAs), or wireless single-purpose devices to perform any of the following:

(i) catalyse the process and organisation for teaching/learning on the go,

(ii) foster instant communications/collaboration, (iii) conduct assessments/evaluations,

(iv) provide access to support/knowledge.

\section{Barriers to Adoption of m-Learning}

Sharples suggests that technical aspects are apart from minor impediments such as battery life and lack of availability of Flash in iPhones; we are currently limited by (a) paucity of imagination, (b) lack of appropriate business models, and (c) poverty (inaffordability) [57], http://www.learningsolutionsmag.com/articles/473/mobile-learning-obstacles-andsolutionsI.

Currently, parts of curricula can be disaggregated for mlearning, but placing the full course on what is a small screen is neither convenient nor pedagogically sound. As Wagner [58] points out, "... complicated key controls and difficult to read screen presentations will be tolerated only under certain very limited conditions.... For broad and long term adoption, the experience really does matter."

While the screen size is a critical barrier to m-learning with current devices, in the future, the iPhone with Flash \& Flash Lite, and especially the iPad which has the facility to enlarge font sizes and give access to e-books, may reduce this problem, though perhaps not eliminate it. Today there is increasing interest in problem-based learning and collaborative and cooperative instructional practices that reflect the professional practice of people who may be located in different places. The Internet is a powerful social networking tool that encourages the development of online communities of practice that prepare students to work in virtual teams [59]. However, mobile hand-held tools do not easily allow collaboration unless used in conjunction with face-to-face (blended) learning and online learning [18]. The process of education involves both cognitive connectivity and social connectivity for problem-based learning, and innovative and critical thinking demands deep concentration devoid of environmental distractions and easy access and connectivity to databases and the Internet. Currently, content developed for other media does not transfer well for different platforms. According to Murphy [60], if we really want to unleash our creativity, we may need to go "unplugged" as "... it is not at all evident that there are any technological short cuts that can speed up the process of thought" [60, page 24].

While mobile learning continues to be a topic of interest among educators, very few institutions in the US have adopted it [61]. Judy Brown, a key thinker in mobile learning strategies, suggests some questions that institutions considering a mobile learning initiative should consider. A critical question for teachers is what they expect from m-learners: for example, will learners be consumers of content? Expect students to create content? Or both? For discussion, see http://www.academicimpressions.com/newsCMS.php?i=42.

Marshall McLuhan's maxim, "the medium is the message," is as relevant today as it was revolutionary when he coined it in 1967. The last 50 years has seen the development of a number of technologies, including radio, television, computers, satellites, fibreoptics, telecommunications, 
the Internet, wireless, and multimedia, that promised a learning revolution. Many of the technologies did not live up to their promise, mainly because we have privileged each new medium at the expense of designing the message appropriately. There is a dearth of published research on instructional/course design for m-learning. It is critical to research this area to ensure more effective ways of delivering the promise of new technologies for higher education.

Rheingold wrote Virtual Reality [62]. In a sequel, he proved to be remarkably perceptive when he noted that "... we are on the brink of having the power of creating any experience we desire" [43, page 360]. In the last decade of the twentieth century, virtual reality technology that allows fully immersive environments has already had an effect on many of our transactions, such as banking, shopping, gaming, and learning. Today we see, particularly in the gaming industry, mobile technology providing streaming video, podcasting, and fully immersive environments in real time.

According to Quinn [51], despite the promise of opportunities, m-learning faces a number of barriers, including the problem of managing learning through intermittent connections (author's emphasis) and the lack of crossplatform solutions that give all learners access to all materials independent of the devices they use.

What is needed includes the following:

(i) a standard set of tools to develop m-learning,

(ii) a sound theoretical m-learning framework,

(iii) autoadaptation to different platforms so that what is developed will work across multiple devices,

(iv) good examples of research on sustainable m-learning,

(v) the capability of integrating m-learning with LMS,

(vi) course/instructional design for m-learning.

\section{Conclusion}

To explore the potential for mobile learning to constitute a new paradigm of higher education, this paper examines some of the opportunities and challenges for m-learning to improve student learning outcomes. Technological advances such as mobile technology are considered as an extension of the framework of more traditional e-learning environments to support constructivist, self-directed interactive learning. A review of some empirical literature on the current status of mobile learning highlights the need for the development or adaptation of learning theory for m-learning and critical frameworks to evaluate the use of mobile technologies that increase access to quality education for increasingly mobile learners seeking just-in-time and just-for-me education solutions.

In the last two decades, the claims of new paradigms of teaching and learning have been a focus for academic researchers in higher education. However, the lack of the major sustainable success anticipated in universities and other organisations that opt for online learning is notable in the empirical evidence. Mostly, mobile learning scenarios are restricted to short-lived, short-funded pilot projects or to researchers using individual courses as experiments outside mainstream methods offered by their institutions, in an effort to overcome the experimental status of m-learning.

Some issues relating to education "on the go" need urgent address before we can assess the potential of m-learning to provide a new educational paradigm. These include the adaptation of the neo-Vygotskyian theoretical framework for m-learning, the need to satisfy the demands of those learners who will be using mobile systems, and the need to achieve measurable learning outcomes while considering the demands of faculty time.

Staff development in adapting course/instructional design and online teaching techniques for m-learning are critical. Instruction for conventional e-learning must be redesigned for m-learning for deep learning to take place. Conducting assessments and giving feedback in a mobile environment, though very important in sustaining the teaching/learning relationship, needs further research as do the development of support systems for students to learn how to learn in a mobile environment capitalising on the strengths of m-learning. For example, short messages regarding timetabling, assignments due dates, and changes in class times are important aspects of managing education, and m-learning devices are ideally placed to effectively enable this process.

Whether m-learning is sustainable, pedagogically sound real learning, and relevant for all subject domains, and all learning styles, in all contexts and cultures, calls for further urgent investigation. After all, while distance education has a long pedigree in the last 100 years or so, it is still to earn the status of a new paradigm in higher education.

A search of the literature and documented praxis suggests that, while m-learning is proving to be innovative and seductive, the factors that most strongly impact on the ultimate success or failure of m-learning will depend on human factors, the balancing of technological ideals and pedagogical imperatives, and the successful management of the interface between human educational systems and technology systems. It is too early to predict whether mlearning will constitute a new paradigm of higher education or like some of its antecedents such as ETV prove to be an educational short-lived fad. However, because the way we live, work, play, bank, shop, and learn is being profoundly affected by the increasing mobility of our society, it is the responsibility of educators and researchers to design for the needs of their changing audience. Not to research and address this phenomenon for instant gratification and learning on the go for the mobile generation may find us unprepared for future realities.

\section{References}

[1] L. Rajasingham, Critical Factors for Successful E-Learning: A Case Study of the Universitat Oberta de Catalunya, E-Learn Centre, Internet Interdisciplinary Institute (IN3), Barcelona, Spain, 2010.

[2] J. Tiffin and L. Rajasingham, In Search of the Virtual Class: Education in an Information Society, Routledge, New York, NY, USA, 1995. 
[3] J. Tiffin and L. Rajasingham, The Global Virtual University, Routledge, New York, NY, USA, 2003.

[4] T. Kuhn, The Essential Tension: Selected Studies in Scientific Tradition and Change, University of Chicago Press, Chicago, Ill, USA, 1977.

[5] T. Kuhn, The Structure of Scientific Revolutions, University of Chicago Press, Chicago, Ill, USA, 1962.

[6] K. Olsevicova, "Topic maps e-Learning portal development," The Electronic Journal of E-Learning, vol. 4, no. 1, pp. 59-66, 2006.

[7] Sloan Consortium, "Sloan-C Five Pillars of Quality Online Education," 2002, http://www.sloan-c.org/5pillars.

[8] T. Ng'andwe, "Mobile phone learning on the move in Africa," in Proceedings of the 6th International Conference on ICT Development, Education and Training, Dar es salaam, Tanzania, May 2011, http://www.elearning-africap.com/newsportal/english/news249.php.

[9] "Internet World Stats," (Africa Internet Usage and Population Stats).

[10] UNCTAD, Information Economy Report, 2009, http://www .unctad.org/en/docs/ier2009_en.pdf.

[11] eLearning Africa, January 2009, http://www.elearning-africa .com/newsportal/english/news249.php.

[12] W. Haddad and A. Drexler, "The dynamics of technologies for education," in Technologies for Education: Potentials, Parameters, and Prospects, W. Haddad and A. Drexler, Eds., p. 9, Academy for Educational Development and Paris: UNESCO, Washington, DC, USA, 2002.

[13] O. Zawacki-Richter, T. Brown, and R. Delport, "Mobile learning: from single project status into the mainstream?" European Journal of Open, Distance and E-Learning, vol. 2009, no. 22, Article ID 4703795, 2009.

[14] M. Sharples, 2004, http://mlearning.noe-kaleidoscope.org/ repository/TheoryOfLearningForMobileAge.pdf.

[15] “eLearning Guild," 2009, http://www.elearningguild.com/ showFile.cfm?id=3673.

[16] J. Wang, X. Li, T. Huang, and B. Wu, "Personalized knowledge service framework for mobile learning," in Proceedings of the 2nd International EEEC Conference on Semantics Knowledge and Grid (SKG '6), November 2006.

[17] T. T. Goh and V. Hooper, "To TxT or not to TxT: that's the puzzle," Journal of Information Technology Education, vol. 6, 2007.

[18] R. Shen, M. Wang, and X. Pan, "Increasing interactivity in blended classrooms through a cutting-edge mobile learning system," British Journal of Educational Technology, vol. 39, no. 6, pp. 1073-1086, 2008.

[19] N. M. Doering, "The mainstreaming of mobile learning at a German University," in Proceedings of the 5th Annual IEEE International Conference on Pervasive Computing and Communications Workshops (PerCom '07), pp. 159-164, 2007.

[20] J. Traxler, "Defining, discussing, and evaluating mobile learning: the moving finger writes and having writ..," International Review of Research in Open and Distance Learning, vol. 8, no. 2, article 8.2.2, 2007.

[21] D. Metcalfe, "mLearning: learning anywhere," in Proceedings of the Online Learning Conference, Anaheim, Calif, USA, 2002.

[22] A. Romiszowski, "How's the e-learning baby? Factors leading to success or failure of an educational technology innovation," Educational Technology, vol. 44, no. 1, pp. 3-27, 2004.

[23] S. Caudron, "Evaluating e-degrees," Workforce, vol. 80, pp. 4448, 2001.
[24] M. Castells, M. Fernandez-Ardévol, J. Qui, and A. She, Mobile Communication and Society, MIT Press, Cambridge, Mass, USA, 2007.

[25] M. Castells, The Rise of the Network Society, Blackwell Publishers, Oxford, UK, 2000.

[26] M. Castells, Communication Power, Oxford University Press, Oxford, UK, 2009.

[27] A. Bates, Technology, Open Learning and Distance Education, Routledge, London, UK, 1995.

[28] C. Latchem and D. Hanna, "Open and flexible learning: an environmental scan," in Leadership for 21st Century Learning, C. Latchem and D. Hanna, Eds., pp. 1-14, Kogan Page, London, UK, 2001.

[29] C. Christensen, Disruptive Technologies: Catching the Wave, Harvard Business Review, 1995.

[30] C. Christensen, Innovator's Dilemma: When New Technologies Cause Great Firms to Fail, Harvard Business Press, Cambridge, Mass, USA, 1997.

[31] W. Tierney and G. Hentschke, New Players, Different Game: Understanding the Rise of For-Profit Colleges and Universities, Johns Hopkins University Press, Baltimore, Md, USA, 2007.

[32] J. Roschelle and R. Pea, "A walk on the WILD side: how wireless handhelds may change CSCL," in Proceedings of the Computer Support for Collaborative Learning (CSCL '02), Boulder, Colo, USA, January 2002.

[33] "Megatrends," 2007, http://www.ericsson.com/ericsson/corpinfo/programs/the_role_of_mobile_learning_in_european_education/products/wp/socrates_mlearning_wp4.pdf.

[34] L. Motiwalla, Mobile Learning: A Framework and Evaluation, Elsevier, Amsterdam, The Netherlands, 2007.

[35] M. Ito and M. Matsuda, Personal, Portable, Pedestrian: Mobile Phones in Japanese Life, MIT Press, Cambridge, Mass, USA, 2005.

[36] V. Harrington and P. Mayhew, "Mobile phone theft," Research Study 235, 2001, http://www.homeoffice.gov.uk/rds/ pdfs/hors35.pdf.

[37] H. Ryu and D. Parsons, Innovative Mobile Learning, Information Science, New York, NY, USA, 2009.

[38] M. Moore, "Theory of transactional distance," in Theoretical Principles of Distance Education, D. Keegan, Ed., pp. 22-38, Routledge, New York, NY, USA, 1997.

[39] J. Daniel, "Learning for development," 2007, http://www .col.org/SiteCollectionDocuments/speeches3_web.pdf.

[40] L. Vygotsky, Mind in Society, Harvard University Press, Cambridge, Mass, USA, 1978.

[41] M. T. H. Chi, J. D. Slotta, and N. De Leeuw, "From things to processes: a theory of conceptual change for learning science concepts," Learning and Instruction, vol. 4, no. 1, pp. 27-43, 1994.

[42] H. U. Hoppe, R. Joiner, M. Milrad, and M. Sharples, "Guest editorial: wireless and mobile technologies in education," Journal of Computer Assisted Learning, vol. 19, no. 3, pp. 255259, 2003.

[43] H. Rheingold, The Virtual Community: Homesteading on the Electronic Frontier, MIT Press, Cambridge, Mass, USA, 1993.

[44] R. Van Eck, "Digital game-based learning," Educause Review, pp. 17-30, 2006.

[45] S. Starr, "Application of mobile technology in learning \& teaching: 'M-learning,' Tech. Rep., Canterbury Christ Church University, 2003, http://www.canterbury.ac.uk/Support/learning-teaching-enhancement-unit/Resources/Documents/Briefing-Notes/MLearning.pdf\#search =\%22Starr\%22. 
[46] A. Gaskell, “Editorial,” Open learning, vol. 22, p. 1, 2007.

[47] T. Brown, "The role of m-learning in the future of e-learning in Africa," 2004, http://www.springerlink.com/content/ j31482653j7r7161/.

[48] M. Lee and A. Chan, "Pervasive, lifestyle-integrated mobile learning for distance learners: an analysis and unexpected results from a podcasting study," Open Learning, vol. 22, no. 3, pp. 201-218, 2007.

[49] A. Bachan, "Producer," M-Learning school. Podcast, July 2008, http://www.youtube.com/watch?v=0bh3HP51rJs.

[50] Y. Laouris and N. Eteolkeos, "We need an educationally relevant definition of mobile learning," in Proceedings of the 4th World Conference on Mobile Learning (mLearn '05), Cape Town, South Africa, October 2005.

[51] C. Quinn, "mLearning: Mobile, wireless, in-your-pocket learning," 2000, http://www.linezine.com/2.1/features/cqmmwiyp .htm.

[52] P. Harris, "Goin' mobile, learning circuits," Archives, ASTD, 2001.

[53] D. Keegan, The Future of Learning: From Learning to mLearning, Hagen, FernUniversität, 2002.

[54] D. P. Ausubel, "The use of advance organizers in the learning and retention of meaningful verbal material," Journal of Educational Psychology, vol. 51, no. 5, pp. 267-272, 1960.

[55] R. Mayer, Learning and Instruction, Pearson Education, New Jersey, NJ, USA, 2003.

[56] H. Ryu, "Designing situated learning experiences," in Innovative Mobile Learning, H. Ryu and D. Parsons, Eds., pp. 255-272, Information Science, New York, NY, USA, 2009.

[57] M. Sharples, 2010, http://www.learningsolutionsmag.com/ articles/473/mobile-learning-obstacles-and-solutionsI.

[58] E. Wagner, "Enabling mobile learning," Educause Review, vol. 40, no. 3, pp. 40-53, 2005.

[59] D. Hanna, "Higher education in an era of digital competition: global consequences," in Higher Education in an Era of Digital Competition: Choices and Challenge, D. Hanna and Associates, Eds., pp. 19-44, Atwood Publishing, Madison, Wis, USA, 2000.

[60] P. Murphy, "You are wasting my time," The University of Auckland Business Review, vol. 9, no. 2, pp. 17-26, 2007.

[61] “Campus Technology,” January 2009, http://www.academicimpressions.com/news.php?i=42\&q=6374e409285eA

[62] H. Rheingold, Virtual Reality, Summit Books, New York, NY, USA, 1991. 


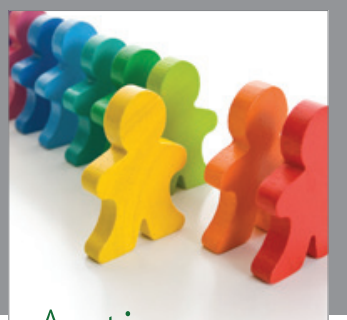

Autism

Research and Treatment
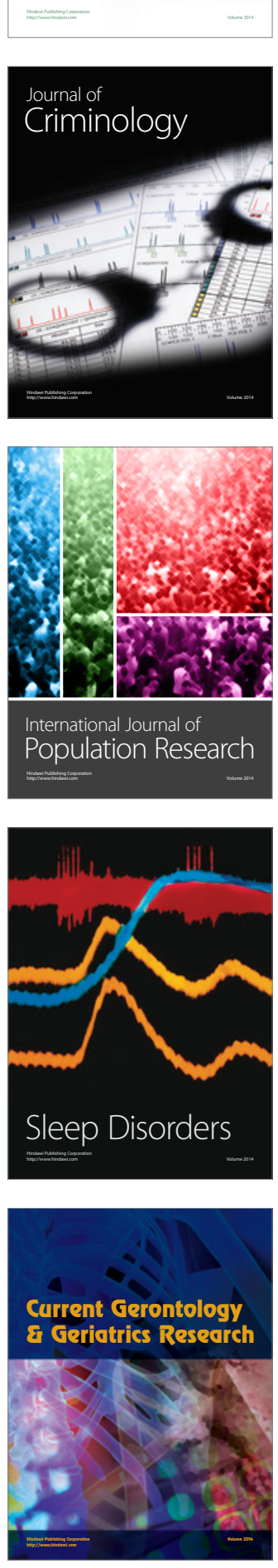
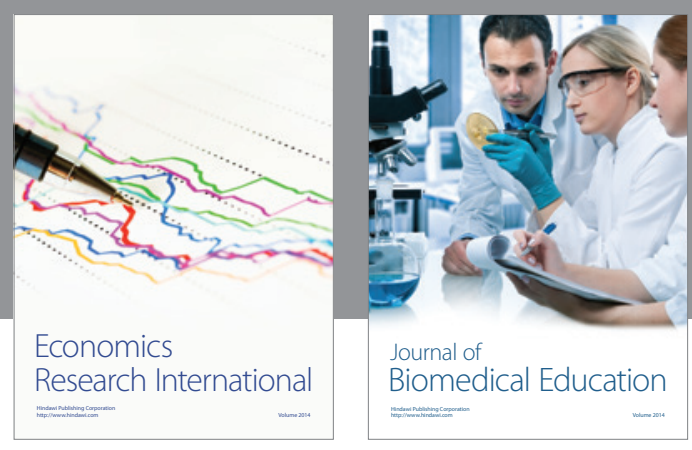

Journal of

Biomedical Education

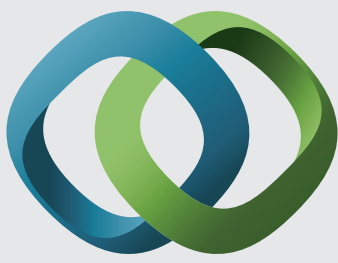

\section{Hindawi}

Submit your manuscripts at

http://www.hindawi.com
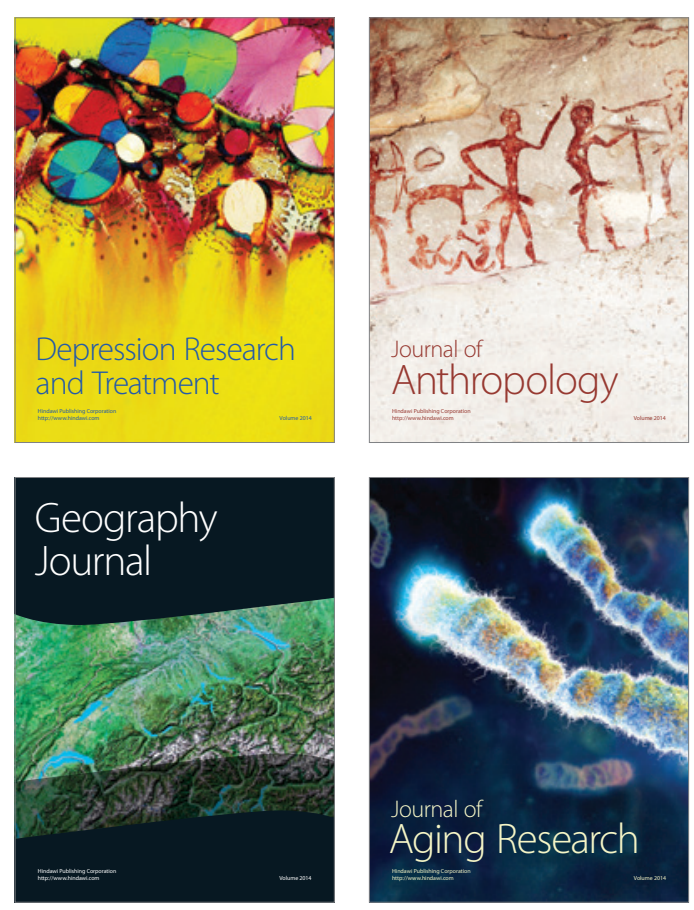

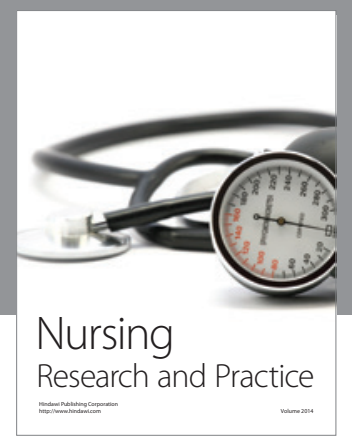

Nursing

Research and Practice

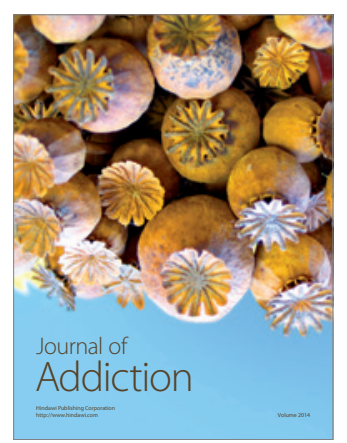

Child Development

Research

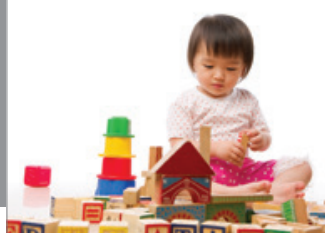

迥
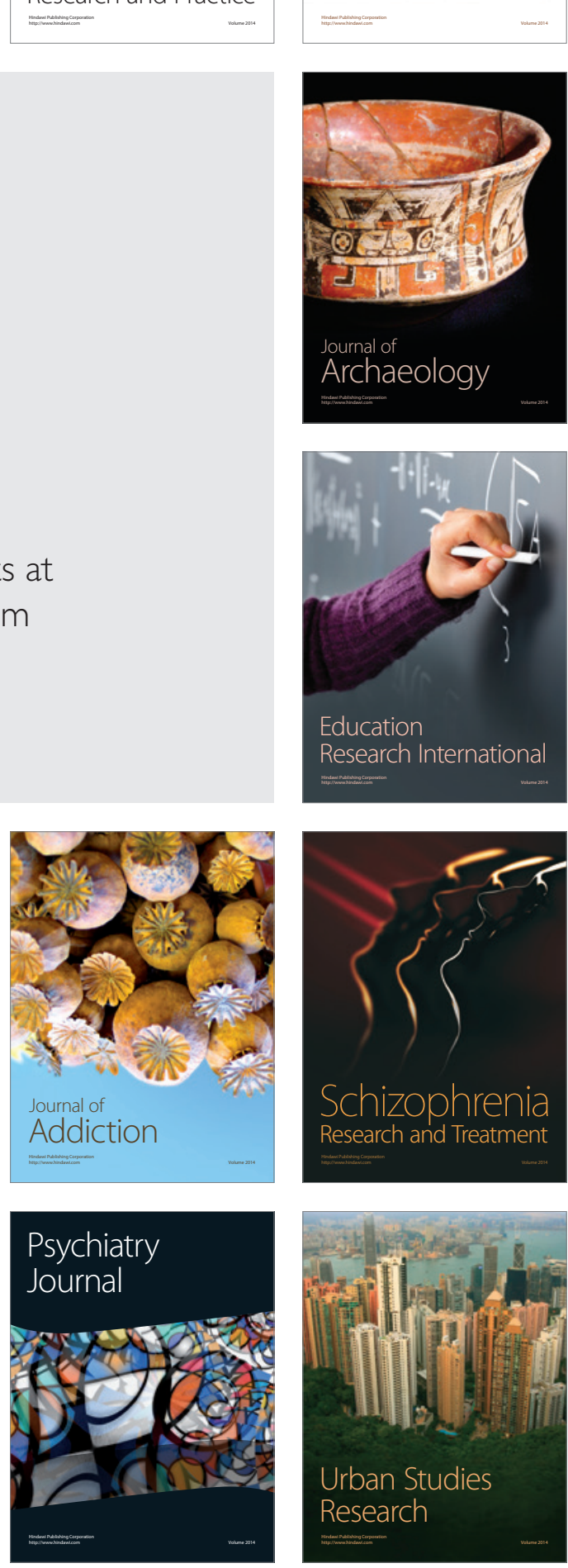